\title{
Does gender predict emotional intelligence among adolescents?
}

\author{
Mary Rachelle R Wapaño, PhD \\ Kinaadman Research Center, Xavier University - Ateneo de Cagayan, Philippines
}

\begin{abstract}
This study seeks to answer this question: Does gender predict emotional intelligence among adolescents? There were 300 study participants by random sampling.

Of the 300 respondents, $166(55 \%)$ were females and $134(45 \%)$ were males. The average age of respondents was19.10 years $(S D$ = 1.956). Emotional intelligence is defined from the standpoint of the Mayer and Salovey EI model: as the ability to "perceive emotions, to access and generate emotions so as to assist thought, to understand emotions and emotional meanings, and to reflectively regulate emotions to promote both better emotion and thought" (Mayer \& Salovey,1997, p. 5). The trait meta-mood scale was the first assessment measure developed by the authors who first identified the EI construct. The TMMS was designed to measure individual differences in the processes of emotional regulation, which includes emotional awareness that further involves monitoring, evaluation, and management of feelings. For total EI score, female respondents $(n=166)$ obtained mean score of $87.64(S D=8.87)$, whereas male respondents $(n=134)$ obtained a mean score of $87.37(S D=9.38)$. For EI subscale emotional attention, females obtained a mean score of $44.67(S D=$ 5.68); whereas males obtained a mean score of $43.51(S D=6.29)$. For subscale emotional clarity, females obtained a mean score of 24.20 $(S D=3.85)$, whereas males obtained a mean score of 25.77 $(S D=3.96)$. For subscale emotional repair, females obtained a mean score of $15.68(S D=2.62)$, whereas males obtained a mean score of $15.28(S D=2.64) \quad$.
\end{abstract}

To test if gender significantly predicts the level of emotional intelligence of college respondents, multiple regression analysis was used. The results of the regression indicate that gender does not explain any of the variance in emotional intelligence $\left(R^{2}=.000, F(1,298)=.070, p=.792\right)$. Gender does not significantly predict emotional intelligence among adolescents $(\beta=-.015, p=$ $.525)$.

\section{INTRODUCTION}

$\mathrm{E}$ motional intelligence is a concept rooted in Thorndike's 1937 social intelligence which refers to one's ability to understand and deal with other people and to engage in meaningful, adaptive interaction with them (Thorndike, 1920, as cited in Zeidner et al., 2009). This is thought to be the individual's ability to process and utilize emotional information related to key areas of effective functioning in everyday life (Mayer \& Salovey, 1997). It is a combination of factors that is found to be related to motivation (Christie, Jordan, Troth, Lawrence, 2007); impulse control (Tice, Bratslavsky, \& Baumeister, 2001); mood regulation (Gohm) 2003 and the ability to persist in the face of frustration (Yoo \& Salovey, 2008). Evidence reveals that emotional intelligence is a predictor of academic (Downey,
Mountstephen, Lloyd, Hansen, \& Stough, 2008) and professional (Abraham, 2005) success.

Among adolescents, emotional intelligence is found to help reduce stress by decreasing conflict, improving relationships and understanding one's own emotions. This kind of emotional health is fundamental to effective learning and education (Serrat, 2009). Understanding the process and elements of learning, which necessarily involves self-efficacy, self-regulation, and ability to communicate and cooperate, in themselves essential aspects of emotional intelligence, are also critical to student success (Zimmerman, Bandura, \& Pons, 1992). Stressful events, such as starting college life, moving to a new city, separation from friends, or loss of a parent, can prompt the onset of anxiety symptoms among adolescents. Among adolescents, anxiety disorder can be difficult to diagnose as an adolescent's behavior is often attributed to being "just a phase." When not addressed or left untreated, anxiety disorders can persist and interfere severely with an adolescent's life and can lead to missed school days, strained peer relations, low self-esteem, alcohol or substance abuse (Stein \& Hollander, 2001).

Emotional intelligence has a protective effect against suicidal ideation and attempts (Cha \& Nock, 2009); against stress (Mikolajczak, Menil, \& Luminet, 2007); and against depression (McDougall, 2006). Moreover, studies reveal that emotional intelligence has a facilitative effect on overall health and life satisfaction (Landa, Zafra, Martos, \& AguilarLuzón, 2006).

Adolescents face formidable challenges in emotional development (Conger \& Galambos, 1997). Their stilldeveloping sense of self and emotional competence correspond to the times when they face demands in school, or stresses in family life, and strong need to fit in among friends. The cost of emotional deficiency among adolescents is disturbing such as increased depression and anxiety (Fernández-Berrocal, Alcaide, Extremera, \& Pizarro, 2006) whereas developing their emotional abilities may improve their coping skills which in turn may produce better mental health in the long term (Downey, Johnston, Hansen, Birney, \& Stough, 2010). The current EI studies are concerned with the model- and measure-development applied to managerial performance with adult respondents. Little research had been done that examined the adaptive function of emotional intelligence among adolescents (Malekar \& Mohanty, 2009). 
Mayer and Salovey (2004) describe emotion as one of three or four sets of mental operations. Motivation, identified as the first set of mental processes, is activated as a response to physical drive such as hunger, thirst or sexual needs, which directs organism to satisfy its survival needs. They further proposed that emotions seemed to evolve among mammalian species to point to actual or perceived changes in the environment and to elicit responses to a changing environment, whereas cognition allows the organism to solve problems and learn from its environment and includes learning, memory, and problem solving, information processing that is conscious and flexible (Mayer \&Salovey, 2004). The term emotional intelligence suggests the converging of emotion and cognition.

Sternberg (1997) defines intelligence as a "necessity of mental ability for adaptation in, or shaping or selection of any environmental context, not just in any one particular environmental context" (p. 1033). This is similar to the definition proposed by Weschler in 1958 as the individual's "global capacity to act purposely, to think rationally, and to deal effectively with his environment" (as cited in Mayer \& Ciarrochi, 2006, p. 262). The term "intelligence" generally implies information gathering, processing the information gathered, and reasoning using information. In 1921, Terman (as cited in Sternberg, 2000) described an intelligent individual as one who can perform abstract thinking. Traditionally, abstract thinking has been considered as a significant indicator of intelligence. Typically, intelligence is regarded as intellectual capacity for problem-solving, analysis, and abstract reasoning.

Drawing from this cooperative combination of intelligence and emotion, emotional intelligence may be defined as a generic ability in perceiving emotions in oneself and in others, in managing emotions, and in coping effectively in emotionalladen situations (Zeidner, Matthews, \& Roberts, 2009).

The concept of emotional intelligence can be traced to John Dewey's conception of social intelligence in 1909: The "ultimate moral motives and forces are nothing more or less than social intelligence - the power of observing and comprehending social situations - and social power-trained capacities of control-at work in the service of social interests and aims" (Landy, 2006, p.84). Similarly, Thorndike in 1920 described social intelligence as "the ability to manage and understand men and women, boys and girls, to act wisely in human relations" (as cited in Zeidner et al., 2009, p. 6).

\section{MAYER AND SALOVEY FOUR-BRANCH MODEL}

The Mayer and Salovey EI model (Salovey \& Mayer, 1990) integrates key concepts from the theories of intelligence and emotion. The notion that intelligence involves the capacity to carry out abstract reasoning comes from intelligence theory while the notions that emotions are indicators that communicate general and understandable meaning about relationships and that certain emotions are basic as they are universal come from emotion research (Mayer, Salovey, \&
Caruso, 2002 ). The Mayer and Salovey model proposed that there are individual differences in how people process emotion-laden information and how they relate emotional processing to general cognition.

The capacity to reason about emotions, and of emotions to enhance thinking. It includes the abilities to accurately perceive emotions, to access and generate emotions so as to assist thought, to understand emotions and emotional knowledge, and to reflectively regulate emotions so as to promote emotional and intellectual growth (p. 197).

The mental ability model of Mayer and Salovey (2000) conceives of emotional intelligence as similar to other intelligences such as cognitive intelligence to the extent that it meets three empirical requirements. Mayer, Salovey and Caruso EI model (2000) enumerates these criteria: First, mental problems have definite correct and incorrect answers assessed by systematic scoring method; second, EI correlates with other measures of mental ability; and third, ability increases with age.

The use of integrated definition of emotional intelligence within the ability model has many scientific advantages: The ability model definition excludes personality attributes, such as initiative, as this is conceptually separable from and is not directly associated to emotional intelligence. The clarity of the EI definition within the ability model allows scholars and practitioners to communicate clearly about the subject matter that is measured or studied, to effectively integrate EI with other variables being studied, to differentiate EI from other personality variables, to use measures with confidence that the measure will assess the EI (Mayer, et al., 2000).

The Mayer and Salovey EI model predicts that individuals with high levels of emotional intelligence have probably been raised with emotionally adaptive households; are less likely to act defensively; are able to perceive emotional issues effectively; choose healthy role models for emotional health; are able to express their feelings openly, and have knowledge in specific areas such as social problem-solving, moral or spiritual feelings, and leadership (Mayer \& Salovey, 1995).

Furthermore, this EI model also predicts that individuals with higher levels of emotional intelligence are likely to have better social support and fewer problematic relations; are more satisfied with their social interactions and appear to receive more social support; and they seem to be more successful at evading fights of a social nature, arguments or interpersonal violence.

\section{GENDER DIFFERENCES IN EMOTIONAL INTELLIGENCE.}

There is currently conflicting evidence on whether or not males or females differ significantly in levels of emotional intelligence. For example, Goleman (1995) advanced that there is no gender difference in EI, stating that men and women have different levels of strengths and weaknesses in different areas of EI, and suggesting that their EI levels are, in 
general, equivalent. However, Mayer and Geher (1996), and Mayer, Caruso and Salovey (1999) found that women tended to have higher emotional intelligence scores than men, both in professional and personal situations.

The inconsistency of results in gender-difference EI studies may be due to the kind of measure used, which may either be a self-report measure or a performance measure. On the one hand, scales or self-report measures refer to information that the subject provides related to his or her own perception of their own EI by responding to a series of questions. On the other hand, performance measures or ability tests are similar to conventional cognitive performance or intelligence tests in which subjects are asked to determine emotional problems. Their responses are then compared to predetermined objective scoring criteria (Mayer, 2001).

EI studies that used self-report measures such as Bar-On Emotion Quotient Inventory (EQ-i) and the Self-Report Emotional Intelligence Test (SREIT) found no evidence for gender differences. However, in some cases where ability measures of emotional intelligence were used, women showed more skill in recognizing and regulating emotions than do men (Adeyemo, 2008; Alkhadner, 2007; Alumran \& Punamaki, 2008; Harrod, 2005). In others, women are shown to have higher scores in emotional attention and empathy, and men are revealed to have higher scores at regulating emotions (Bindu\& Thomas, 2006; Fernandez-Berrocal, Extremera, \& Ramos, 2000; Harrod \& Scheer, 2005). The differing results may be attributed to the sample's demographic characteristics or the kind of measure being used.

In other self-report scales such as the Trait-Meta Mood Scale48 (TMMS-48), the differences found tend to favor women, who are shown to be more attentive to their emotions than do men. Women tended to be more skillful in dealing with, and understanding their emotions, and men are better at directing impulses and enduring stress (Fernandez-Berrocal, Alcaide \& Ramos, 1999; Fernandez \& Extremera, 2003). However, when performance measures were used, such as the Mayer-SaloveyCaruso Emotional Intelligence Test (MSCEIT), there were clear differences in EI with women scoring higher than men (Brackett \& Mayer, 2003).

Studies on gender differences on EI using self-report and performance measures reveal significant results: men tended to report a higher EI compared to how they subsequently perform; while women tended to report a lower EI than they show in performance tests (Bracket \& Mayer, 2003). Even with evidence showing that women in general have higher EI scores than men, their self-perception tended to be lower than that of men. Research has shown that there is a link between low self-reported EI levels and poor mental health, indicated by depression, anxiety, and emotional adjustment scales, among women (Fernandez-Berrocal, Alcaide, Extremera,\&Pizzaro, 2006). With these poor mental health indices, women tended to develop more mental health disorders than do men (Caro Gabalda, 2001).
In general, then, it appears that women tend to show greater emotional knowledge, provide more detailed emotional descriptions, and use more emotional words than men. These results reflect gender differences related to efficiency of and accessibility to emotional knowledge, and motivation to use emotional knowledge. Although the review presented gender difference in emotional competencies, it is also possible that these gender stereotypes are beginning to change from what is considered conventional (Baron-Cohen, 2005).

Popular literature presents conflicting results. Some studies demonstrate significant gender difference while others do not. The reviewed literature has, thus, demonstrated some degree of relationship between gender and emotional intelligence.

However, this relationship has not been clearly established in an adolescent, Filipino sample. In the light of the literature reviewed, there is then a need for further research in this area.

This study seeksto answer this question: Does gender predict emotional intelligence among adolescents?

\section{STUDY DESIGN}

This study is a predictive- research. As a predictive research, this study aimed to examine how the following variables: gender, predict emotional intelligence. In this study, gender was taken as categorical predictor variable. Gender, with two levels, was directly entered as predictor variable in the analyses

\section{Participants}

The sample size for this study is 300 study participants. This study specifically targeted college students as it has been shown that there was increased frequency of mental health concerns among college students that need to be systematically addressed. Hence, random sampling was usedin this study.

Of the 300 respondents, 166(55\%) were females and 134 $(45 \%)$ were males. The average age of respondents was 19.10 years $(S D=1.956)$.

\section{MEASURE}

In this study, Trait Meta-Mood Scale (TMMS) was used to assess emotional intelligence.

Emotional intelligence is defined from the standpoint of the Mayer and Salovey EI model: as the ability to "perceive emotions, to access and generate emotions so as to assist thought, to understand emotions and emotional meanings, and to reflectively regulate emotions to promote both better emotion and thought" (Mayer \& Salovey,1997, p. 5). The trait meta-mood scale was the first assessment measure developed by the authors who first identified the EI construct. The TMMS was designed to measure individual differences in the processes of emotional regulation, which includes emotional awareness that further involves monitoring, evaluation, and management of feelings (Mayer, Salovey, Goldman, Turvey, 
Palfai, 1995) (Appendix B). The TMMS is based on the early notions of EI put forth by Mayer and Salovey (1990).

The TMMS assessed the extent to which individuals attend to their feelings, the clarity of their experience of these feelings, and their ability to regulate their feelings. The TMMS is found to be useful in identifying core individual differences that describe emotionally intelligent individuals. Early EI studies by Mayer and Gaschke (1988) showed that individuals regularly reflect, monitor, evaluate, and manage their feelings; they termed this process as meta-mood experience. The TMMS is designed to assess "relatively stable individual differences in people's tendency to attend to their moods and emotions, discriminate clearly among them, and regulate them (Salovey, Mayer, Goldman, Turvey, \&Palfai, 1995, p.128). It is designed to measure three EI constructs, namely, attention to emotion, clarity of emotion, and emotion repair. Attention to emotion conveys the extent to which individuals notice and think about their feelings; clarity of emotions refers to the ability to understand one's moods; and emotion repair pertains to the degree to which individuals regulate their moods.

The TMMS is found to be an adequate operationalization of the aspects of emotional intelligence (Salovey et. al, 1995). This measure is able to assess individual differences in people's ability to understand, express, and regulate their feelings as well as their ability of using their feelings adaptively. The scales in the TMMS, namely, attention to feelings, clarity of feelings, and ability to regulate one's emotions are fundamental to emotional intelligence (Salovey, et al., 1995).

Previously reported internal consistencies for each subscale are high attention to emotion, $\alpha=.86$; emotional clarity, $\alpha=$ .87 ; and emotion repair $\alpha=.82$ (Salovey, et al., 1995). Validation studies have demonstrated that these constructs can be sufficiently differentiated from related constructs such as neuroticism and repression. The use of self-report measures to assess emotional intelligence "provides a straightforward and economical means for measuring individual differences in emotional functioning." (Zeider et al., 2009,p. 27).

A pilot study was conducted $(n=30)$ to test the reliability of measures in August 2009. The TMMS was to found to have acceptable reliability ( 30 items; $\alpha=.78$ ).

The alpha coefficient obtained in this study was .66. The reliability coefficients of the TMMS subscales were as follows: attention to feelings (13 items; $\alpha=.62$ ); clarity of emotions ( 11 items; $\alpha=.45$ ), and repair of emotions ( 6 items, $\alpha=.51)$.

The reliability coefficients of the subscales emotional clarity and emotional were found to be low. As recommended by Field (2006), items which were indicated to decrease the measures' reliability were removed from the original subscale measure. The alpha of emotional clarity subscale increased to .60 (8 items) when items 6,14 , and 15 were deleted. The reliability of emotional repair improved to .62 (4 items) when items 9 and 19 were removed. The TMMS reliability coefficient with items deleted was found to be acceptable at .70. This modified measure was used in the analyses and now named as Trait Meta Mood Scale-Adapted (TMMS-A), and is presented in Appendix B1.

Salovey, et al. (1995) did not specify a clear-cut scoring range for interpreting scores. Total EI scores of the adapted TMMS ranged from low of 25 to high of 125 . Using prorate calculation, scores in the range of 25 suggest a need to work on emotions, scores near 75 suggest a good enough handle on emotions; and 125 suggest excellent emotional skills. For emotional attention subscale: scores near 13 suggest a need to work on emotional awareness; near 39, suggest growing emotional awareness; and 65 is considered excellent emotional attention. For subscale emotional clarity: scores near 8 suggest some confusion; scores near 24 suggest growing clarity; and scores near 40 is excellent emotional clarity. For emotional repair: scores near 4 suggest a need to improve self-regulation; near 12 suggest attempts at emotional repair; and scores near 20 suggest excellent emotional repair.

\section{DATA GATHERING PROCEDURE}

Communication was sent to the appropriate authorities for approval. Informed consent was also sought. Respondents were informed about the nature of the study and their participation and were then tested. Respondents were assured of confidentiality of their results, and were informed that their individual results will be made available for them. They were also informed to raise questions they find unclear. Participants completed seven questionnaires in about an hour and 20 minutes. Completed survey sheets were inspected to check for missing information. Data gathered were then screened, encoded, analyzed, and interpreted.

\section{GENDER AND EMOTIONAL INTELLIGENCE}

In this study, gender was taken as categorical predictor variable. Gender, with two levels, was directly entered as predictor variable in the analyses. For total EI score, female respondents $(n=166)$ obtained mean score of $87.64(S D=$ $8.87)$, whereas male respondents $(n=134)$ obtained a mean score of $87.37(S D=9.38)$. For EI subscale emotional attention, females obtained a mean score of $44.67(S D=5.68)$; whereas males obtained a mean score of $43.51(S D=6.29)$. For subscale emotional clarity, females obtained a mean score of $24.20(S D=3.85)$, whereas males obtained a mean score of $25.77(S D=3.96)$. For subscale emotional repair, females obtained a mean score of $15.68(S D=2.62)$, whereas males obtained a mean score of $15.28(S D=2.64)$.

To test if gender significantly predicts the level of emotional intelligence of college respondents, multiple regression analysis was used. The results of the regression indicate that gender does not explain any of the variance in emotional intelligence $\left(R^{2}=.000, F(1,298)=.070, p=.792\right)$. Gender does not significantly predict emotional intelligence among adolescents $(\beta=-.015, p=.525)$. 
Regression analyses were also employed to examine whether gender significantly predicts each scale of the EI, namely, attention to feelings, clarity of feelings, and emotional repair. The results of the regression indicated that gender explained $.9 \%$ of the variance in attention to feelings $\left(R^{2}=.009\right.$ $F(1,298)=2.841, \quad p=.093)$. Gender does not significantly predict the ability to attend to emotions among adolescents ( $\beta=.-097, p=.208)$.

Regression analysis on clarity of emotions and gender was employed, and results indicated that gender explained 3.9\% of the variance in clarity of feelings $\left(R^{2}=.039, F(1,298)=12.004\right.$, $p<.01)$. Statistical power, computed post-hoc was low at 45 . Gender significantly predicted the clarity of emotions among adolescents $(\beta=.197, p<.01)$. Results of regression analysis indicate that gender did not explain emotional repair, $\left(R^{2}=.006, F(1,298)=.1684, p=.195\right)$. Gender did not predict the emotional repair among ADOLESCENTS $(\mathrm{B}=-.075, P=.195)$.

\section{GENDER AND EMOTIONAL INTELLIGENCE}

Gender was not found to predict general emotional intelligence. Although these results are contrary to initial expectations of this research, these results do not contradict current EI studies. For example, Bar-On (2000) did not find gender difference in overall emotional competencies; however, he found slight differences in some areas: females were found to have better interpersonal skills than their male counterparts, whereas males were found to be better at stress management. Similar studies also yielded similar results: Petrides and Furnham (2000) and Reif (2001) did not find significant difference in total EI, but found difference in a single EI component, emotional clarity, as in this study.

The literature set out previously indicated women to be more emotionally skilled than their male counterparts. However, it is highly possible that sex-role stereotypes, which essentially include expressions of gender-appropriate emotions, are different today from what was generally considered normal then.

Guastello and Guastello (2003) suggested a possible explanation for the lack of gender differences in EI among adolescents is connected with generational changes. They proposed that due to the influence of culture and education, gender difference in emotional intelligence is decreasing in the new generation. They further contended that individuals, male or female, with high levels of EI would tend to express varied and wider gender role behaviors and preferences. Emotional intelligence appears, then, to be incompatible with gender role stereotyping, which dictates the proper expression of emotion, who should express it, and in what circumstances. It then appears that, as the new generation becomes less and less dictated and less confined by gender roles and stereotypes, they become may more androgynous than their older counterparts. In fact, Guastello and Guastello (2003) found androgyny to positively predict emotional intelligence among adolescents.
Additionally, the current results showing males to be better at emotional clarity are consistent with Bar-On's (2000) findings which showed "females to have stronger interpersonal skills than males, but the latter have a higher intrapersonal capacity."(Bar-On, 2006, p.7). The intrapersonal capacity EI dimension in the Bar-On theory (2006) pertains to selfawareness and self-expression. This meta-factor includes five sub factors self-regard or the ability to be aware of and accepting of oneself; emotional self-awareness which involves awareness of emotions; assertiveness, the ability to express one's emotions positively; independence, relates to selfreliance; and self-actualization, the ability to set and achiever personal goals.

Bar-on's (2000) study further showed that women tended to have higher emotional awareness, expressedempathy more frequently, and were more socially responsible than men; whereas men, were found to have higher self-concept, adapted better in demanding situations, were better at problem solving, and were more optimistic than women. Bar-On (2000) found this pattern to be consistent among the population sample he tested.

The results that males have higher scores for emotional clarity, that is, the ability to understand and discriminate among feelings, is supported by other studies among adult samples. For example, Fabio and Palazzeschi (2008) found females scored higher in interpersonal dimension, whereas males scored higher in the intrapersonal. Personality studies by Feingold (1994) supported these findings that women fared better at traits such as agreeableness, trust, and tendermindedness. In contrast, males scored higher at emotional stability.

Other EI studies on gender differences, however, are inconsistent with the results of this study: Adeyemo (2008) and Harrod and Scheer (2005) found significant gender differences in emotional intelligence. EI theorist, Daniel Goleman (1995) argued for gender differences in EI, favoring women. He contends that women, as a group, experience emotions more strongly than their male counterparts.

Contradicting results on gender difference on EI may also be attributed to EI measures used, as self-report measures and performance-based measures yield different information. Selfreport measures provide information on a respondent's perception of his or her own level of EI, whereas in a performance-based measure, respondents are asked to solve problems of emotional nature, and their responses will be compared to preset scoring criteria.

Self-report measures yield disparate results: In some other cases, women were found to be better at managing their own and other's moods (Fernandez-Beroccal, Extremera, \& Ramos, 2004), whereas in others, men were found to be better at emotional regulation (Bindu\& Thomas, 2006, Bracket, Warner, Bosco, 2005). On the other hand, when performancebased measures were used, such as the Mayer-SaloveyCaruso-Emotional-Intelligence Test (MSCEIT), there were 
evident gender differences, favoring females (Extremera, Fernandez-Berocal, \&Salovey, 2006; Ciarrochi, Chan, \&Caputi. 2000). In this study, the measure used was TraitMeta Mood Scale (TMMS) a self-report measure of EI which has been shown to be reliable. TMMS is believed to be a reasonable operationalization of the components of emotional intelligence (Salovey, Mayer, Goldman, Turvey, \&Palfai, 1995).

The disparity in the EI results in terms of gender, then, may be due to the kind of EI tool used and demographic characteristics of the sample. These inconsistent findings in gender differences in adolescents imply a need for further exploration in this area with the use of performance-based EI measures.

Gender had not been shown to predict adolescent EI or any of the components of mental health.

\section{REFERENCES}

[1] Alumran, J., \&Punamäki, R. (2008). Relationship between gender, age, academic achievement, emotional intelligence, and coping styles among Bahraini adolescents.Individual Differences Research, 6(2), 104-119. Retrieved from PsycINFO database.

[2] Aquino, A. (2003). Gender differences and age in a group of web browser's emotional intelligence.Unpublished master's thesis, Universidad Inca Gracilazo de la Vega.Facultad de Psycologia y CienciasSociales, Lima, Peru.

[3] Bindu, P., \& Thomas, I. (2006). Gender Differences in Emotional Intelligence.Psychological Studies, 51(4), 261-268. Retrieved from PsycINFO database.

[4] Brody, L. R., \& Hall, J. A. (2008). Gender and emotion in context. In M. Lewis, J. M. Haviland-Jones, L. Barrett, M. Lewis, J. M. Haviland-Jones, L. Barrett (Eds.), Handbook of emotions (3rd ed.) (pp.

[5] Guastello, D. D., \&Guastello, S. J. (2003). Androgyny, Gender Role Behavior, and Emotional Intelligence Among College Students and Their Parents. Sex Roles, 49(11-12), 663673.doi:10.1023/B:SERS.0000003136.67714.04.

[6] Hindin, M. (2005). Family dynamics, gender differences and educational attainment in Filipino adolescents. Journal of Adolescence, 28(3),

316.doi:10.1016/j.adolescence.2004.12.003.

[7] Keefer, K., Wood, L. M., \& Parker, J. D. A. (2009, June). Assessing emotional intelligence in children and adolescents: Congruence between self-report and parent ratings. Paper presented at the annual meeting of the Canadian Psychological Association, Montreal, Quebec.

[8] Lafferty, J. (2004). The relationships between gender, empathy, and aggressive behaviors among early adolescents. Dissertation Abstracts International, 64, Retrieved from EBSCOhost.

[9] Lewinsohn, P., Gotlib, I., Lewinsohn, M., Seeley, J., \& Allen, N. (1998). Gender differences in anxiety disorders and anxiety symptoms in adolescents. Journal of Abnormal Psychology, 107(1), 109-117. doi:10.1037/0021-843X.107.1.109.
[10] Mayer, J., \& Salovey, P. (1995). Emotional intelligence and the construction and regulation of feelings. Applied \& Preventive Psychology, 4(3), 197-208. doi:10.1016/S0962-1849(05)80058-7.

[11] Mayer, J., \& Salovey, P. (1995). Emotional intelligence and the construction and regulation of feelings.Applied \& Preventive Psychology, 4(3), 197-208. doi:10.1016/S0962-1849(05)80058-7

[12] Mayer, J. \& Salovey, P. (1997). Emotional development and emotional intelligence. Cambridge University Press: New York.

[13] Mayer, J. D., \&Ciarrochi, J. (2006). Clarifying concepts related to emotional intelligence: A proposed glossary. In J. Ciarrochi, J. Forgas, \& J. D. Mayer (Eds). Emotional intelligence in everyday life (2nd ed). New York: Psychological Press.

[14] Mayer, J., Salovey, P., \& Caruso, D. (2004). Emotional intelligence: Theory, findings, and implications. Psychological Inquiry, 15(3), 197-215.doi:10.1207/s15327965pli1503_02.

[15] Mayer, J., Caruso, D., \&Salovey, P. (1999). Emotional intelligence meets traditional standards for an intelligence. Intelligence, 27(4), 267-298.doi:10.1016/S01602896(99)00016-1.

[16] Mayer, J. D., Perkins, D. M., Caruso, D. R., \&Salovey, P. (2001). Emotional intelligence and giftedness.Roeper Review, 23(3), 131137. doi:10.1080/02783190109554084.

[17] Mayer, J., Salovey, P., \& Caruso, D. (2000). Models of emotional intelligence.In R. Sternberg (Ed.), Handbook of intelligence. Cambridge, UK: Cambridge University Press.

[18] Mayer, J., \&Salovey, P. (1995). Emotional intelligence and the construction and regulation of feelings.Applied \& Preventive Psychology, 4(3), 197-208.doi:10.1016/S0962-1849(05)80058-7

[19] Mayer, J., \& Salovey, P. (1997). What is emotional intelligence? In P. Salovey \& D. J. Sluyter(Eds.), Emotional development and emotional intelligence (pp. 3-31). New York: Basic Books.

[20] Mayer, J., Salovey, P., Caruso, D., \& Sitarenios, G. (2003). Measuring emotional intelligence with MSCEIT V2.0. Emotion, 3, 97-105. DOI: $10.1037 / 1528-3542.3 .1 .97$

[21] Nasir, M. \&Masrur, R. (2010). An exploration of emotional intelligence of the students of IIUI in relation to gender, age, and academic achievement.Bulletin of Education and Research, 23(1), 37-51.

[22] Petrides, K. V., \&Furnham, A. (2000). Gender differences in measured and self-estimated trait emotional intelligence. Sex Roles, 42(5-6), 449-461.doi:10.1023/A:1007006523133.

[23] Reiff, H. B., Hatzes, N. M., Bramel, M. H., \& Gibbon, T. (2001). The relation of LD and gender with emotional intelligence in college students. Journal of Learning Disabilities, 34(1), 6678.doi:10.1177/002221940103400106.

[24] Sánchez-Núñez, M., Fernández-Berrocal, P., Montañés, J., \&Latorre, J. (2008). Does emotional intelligence depend on gender? The socialization of emotional competencies in men and women and its implications.Electronic Journal of Research in Educational Psychology, 6(2), 455-474. Retrieved from PsycINFO database.

[25] Trobst, K., Collins, R., \&Embree, J. (1994). The role of emotion in social support provision: Gender, empathy and expressions of distress. Journal of Social and Personal Relationships, 11(1), 4562.doi:10.1177/0265407594111003.

[26] Wall, S. (2003). Men's involvement in the emotional domain of marriage: The influence of family expressiveness, emotional intelligence, and gender role conflict. Dissertation Abstracts International Section A, 64, Retrieved from EBSCO host. 